\title{
Simultaneous in situ generation of hydrogen peroxide and Fenton reaction over Pd-Fe catalysts $\dagger$
}

\author{
Mohammad S. Yalfani, ${ }^{a}$ Sandra Contreras, ${ }^{* a}$ Jordi Llorca, ${ }^{b}$ Montserrat Dominguez, ${ }^{b}$ \\ Jesus E. Sueiras ${ }^{a}$ and Francesc Medina ${ }^{* a}$
}

Received 13th July 2010, Accepted 17th September 2010

DOI: $10.1039 / \mathbf{c 0 c p 0 1 1 5 7 f}$

High mineralization degree of organic compounds can be achieved by a novel environmentally-friendly full heterogeneous Pd-Fe catalytic system, which involves in situ generation of hydrogen peroxide from formic acid and oxygen, and oxidation of organic compounds by Fenton process in a one-pot reaction.

The Fenton process is known as one of the most efficient advanced oxidation processes for the degradation of organic pollutants. ${ }^{1}$ However, the overall performance of the process is influenced by its low mineralization capacity due to the formation of recalcitrant intermediates. ${ }^{2}$ The conventional Fenton process (CFP) requires soluble ferrous ion and $\mathrm{H}_{2} \mathrm{O}_{2}$. Ferrous ion as a homogeneous catalyst requires further treatment due to the formation of sludge. $\mathrm{H}_{2} \mathrm{O}_{2}$ is usually provided by bulk feeding, which does not yield high efficiency. Very recently, the Fenton process has shown good performance with catalytic in situ generated hydrogen peroxide. ${ }^{3}$ In situ produced hydrogen peroxide can be consumed at an appreciable controlled rate prior to decomposition to $\mathrm{H}_{2} \mathrm{O}$ and $\mathrm{O}_{2}$, which leads to an improved performance of $\mathrm{H}_{2} \mathrm{O}_{2}$ in the favorite reaction direction. ${ }^{4}$ Here, we demonstrate for the first time that the $\mathrm{Pd}-\mathrm{Fe}$ catalytic coupling is able to achieve a nearly total degree of mineralization for the Fenton reaction within a full heterogeneous catalytic system under very mild conditions. The catalytic system involves the simultaneous generation of hydrogen peroxide from formic acid and oxygen, the formation of hydroxyl radicals and the oxidation of organic compounds.

Alumina-supported $\mathrm{Pd}-\mathrm{Fe}$ catalysts were synthesized by two different procedures involving co- (denoted as Pd5FeCI) and successive impregnation (see experimental details in ESI $\dagger)$. The latter route was performed twice: in one case (denoted as $\mathrm{Pd} 5 \mathrm{Fe}$ ), palladium was deposited on alumina and then $\mathrm{Fe}$ impregnation was carried out, and in the other (denoted as FePd5), the Fe impregnation took place first and then the Pd was deposited. The Pd and Fe metal contents in the above three samples were 5 and $1 \mathrm{wt} \%$, respectively. A monometallic $\mathrm{Pd} 5 \mathrm{wt} \% / \gamma-\mathrm{Al}_{2} \mathrm{O}_{3}$ (denoted as $\mathrm{Pd} 5 \mathrm{Al}$ ) was also prepared as a reference catalyst.

\footnotetext{
${ }^{a}$ Departament d'Enginyeria Quimica, Universitat Rovira i Virgili, Av. Països Catalans, 26, 43007, Tarragona, Spain.

E-mail: sandra.contreras@urv.cat,francesc.medina@urv.cat; Fax: + 34 977559621: Tel: + 34977559680

${ }^{b}$ Institut de Tècniques Energètiques i Centre de Recerca en Nanoenginyeria, Universitat Politècnica de Catalunya, Av. Diagonal, 647, 08028, Barcelona, Spain

$\dagger$ Electronic supplementary information (ESI) available: Experimental details, $\mathrm{H}_{2} \mathrm{O}_{2}$ generation graph, quantitative TPR data. See DOI: $10.1039 / \mathrm{c} 0 \mathrm{cp} 01157 \mathrm{f}$
}

The palladium loading was chosen from the study of $\mathrm{H}_{2} \mathrm{O}_{2}$ generation from formic acid and $\mathrm{O}_{2}$ over alumina-supported $\mathrm{Pd}$ catalysts with different $\mathrm{Pd}$ loads. The results showed that the highest $\mathrm{H}_{2} \mathrm{O}_{2}$ productivity at the initial time of the reaction which is more adequate for in situ applications was achieved using Pd5Al. ${ }^{3,5}$ Our experiments indicate that this productivity was further enhanced in the presence of Fe (see Fig. 1 in ESI $\dagger$ ).

Phenol as a model pollutant was degraded by the Fenton reaction over $\mathrm{Pd}-\mathrm{Fe}$ catalysts at ambient conditions using $\mathrm{H}_{2} \mathrm{O}_{2}$ generated in situ from formic acid and $\mathrm{O}_{2}$. The results by the $\mathrm{Pd}-\mathrm{Fe}$ catalysts are compared with the corresponding reaction using the $\mathrm{Pd} 5 \mathrm{Al}$ catalyst in the presence of $10 \mathrm{ppm}$ of $\mathrm{Fe}^{2+}$ (homogeneous Fenton catalyst) and CFP using $300 \mathrm{ppm}$ $\mathrm{H}_{2} \mathrm{O}_{2}$ (the amount estimated to be produced in situ by formic acid and $\mathrm{O}_{2}$ over $\mathrm{Pd} 5 \mathrm{Al}$ within $\left.6 \mathrm{~h}\right)^{3}$ and $10 \mathrm{ppm}$ of $\mathrm{Fe}^{2+}$ (Table 1$)$. The reaction rate coefficients $\left(k_{\text {obs }}\right)$ for formic acid and phenol decompositions are calculated by fitting data to a pseudo-first-order kinetics during the first hour. Formic acid decomposition rates for all of the catalysts are within a very narrow range, which indicates that $\mathrm{Fe}$ does not interfere in formic acid decomposition by $\mathrm{Pd} .{ }^{6}$ Phenol degradation over the PdFeCI catalyst proceeds at a rate 2.4 times lower than with Pd5Al. The catalyst also shows lower mineralization activity. Although the $\mathrm{Pd} 5 \mathrm{Fe}$ catalyst oxidizes phenol at a lower rate, its performance in mineralization is slightly better. However, the FePd5 catalyst competes with Pd5Al in phenol oxidation and shows outstanding pollutant compound mineralization ability, especially in comparison with CFP, which is unable to exceed $50 \%{ }^{2 c}$ A higher $\mathrm{H}_{2} \mathrm{O}_{2}$ feeding increases the rate at which phenol disappears, but it results in a lower degree of mineralization. ${ }^{2 b}$ Over Pd5Al and $\mathrm{Pd}-\mathrm{Fe}$ catalysts, formic acid is finished at $4 \mathrm{~h}$, but the mineralization proceeds even in the absence of formic acid. This phenomenon can be attributed to the ability of the catalysts to mineralize intermediates. The stability of FePd5 was proved by adding $20 \mathrm{mM}$ of formic acid as soon as the initial $40 \mathrm{mM}$ was finished, i.e. at $4 \mathrm{~h}$. Fig. 1a shows the phenol degradation profile of this reaction. This graph demonstrates that the second stage of the reaction proceeds at a rate similar to that of the initial phenol oxidation. This proves that the catalyst remains active after $4 \mathrm{~h}$ and that the system is capable of degrading even very low concentrations of pollutant. Most importantly, the achievement of a very high degree of mineralization suggests that such a system has the potential to completely remove all organic intermediates. FePd5 was the most appropriate Pd-Fe catalyst because no measurable leached $\mathrm{Pd}$ or Fe remained at the end of each run. Application of the later process was expanded for the degradation of 2,4-dichlorophenol (DCP, as representative of 

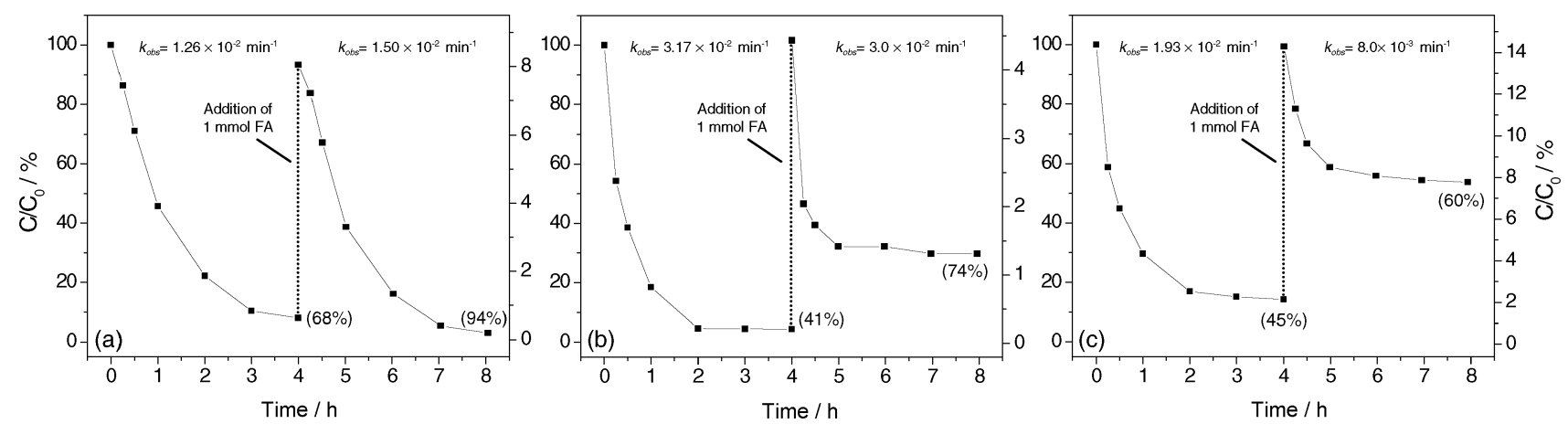

Fig. 1 Organic compounds degradation profiles over FePd5 performed in two steps: (a) phenol, (b) 2,4-dichlorophenol and (c) clofibric acid. After $4 \mathrm{~h}$, an additional $20 \mathrm{mM}(1 \mathrm{mmol})$ formic acid was added. The numbers in parentheses are the corresponding TOC percentages removed at that time.

Table 1 Phenol degradation results by CFP and over Pd5Al and Pd-Fe catalysts

\begin{tabular}{|c|c|c|c|c|c|c|c|}
\hline Catalyst & $t / \mathrm{h}$ & $\begin{array}{l}\text { Ph. } \\
\text { conv. }(\%)\end{array}$ & $\begin{array}{l}\text { TOC } \\
\text { removed }^{a}(\%)\end{array}$ & $\begin{array}{l}\left.k_{\mathrm{obs}(\mathrm{FA} A}\right)^{b} / \\
\min ^{-1}\end{array}$ & $\begin{array}{l}k_{\mathrm{obs}(\mathrm{Ph})}{ }^{c} / \\
\min ^{-1}\end{array}$ & $\begin{array}{l}\text { Pd leached/ } \\
\mathrm{mg} \mathrm{l}^{-1}(\%)\end{array}$ & $\begin{array}{l}\text { Fe leached } \\
\mathrm{mg} \mathrm{l}^{-1}(\%)\end{array}$ \\
\hline \multirow[t]{2}{*}{$\mathrm{Fe}^{2+} 10 \mathrm{mg} \mathrm{l}^{-1 d}$} & 4 & 100 & 45 & - & $\begin{array}{l}1.90 \times 10^{-2} \\
\left(R^{2}=0.9821\right)\end{array}$ & - & - \\
\hline & 6 & 100 & 47 & & & & \\
\hline \multirow[t]{2}{*}{$\mathrm{Pd} 5 \mathrm{Al}+\mathrm{Fe}^{2+} 10 \mathrm{mg} \mathrm{l}^{-1}$} & 4 & 85.3 & 55 & $\begin{array}{l}1.38 \times 10^{-2} \\
\left(R^{2}=0.9996\right)\end{array}$ & $\begin{array}{l}1.71 \times 10^{-2} \\
\left(R^{2}=0.9950\right)\end{array}$ & 0 & - \\
\hline & 6 & 86.3 & 66 & & & & \\
\hline \multirow[t]{2}{*}{$\mathrm{Pd} 5 \mathrm{FeCI}$} & 4 & 72.2 & 47 & $\begin{array}{l}1.29 \times 10^{-2} \\
\left(R^{2}=0.9956\right)\end{array}$ & $\begin{array}{l}7.00 \times 10^{-3} \\
\left(R^{2}=0.9945\right)\end{array}$ & 0 & $0.86(4.3)$ \\
\hline & 6 & 73.6 & 62 & & & & \\
\hline \multirow[t]{2}{*}{$\mathrm{Pd} 5 \mathrm{Fe}$} & 4 & 91.4 & 57 & $\begin{array}{l}1.39 \times 10^{-2} \\
\left(R^{2}=0.9983\right)\end{array}$ & $\begin{array}{l}1.04 \times 10^{-2} \\
\left(R^{2}=0.99926\right)\end{array}$ & 0 & $1.46(7.3)$ \\
\hline & 6 & 93.2 & 72 & & & & \\
\hline \multirow[t]{2}{*}{ FePd5 } & 4 & 91.2 & 68 & $\begin{array}{l}1.33 \times 10^{-2} \\
\left(R^{2}=0.9905\right)\end{array}$ & $\begin{array}{l}1.26 \times 10^{-2} \\
\left(R^{2}=0.9998\right)\end{array}$ & 0 & $<0.1$ \\
\hline & 6 & 92.1 & 78 & & & & \\
\hline
\end{tabular}

chlorophenols) and clofibric acid (CFA, as representative of pharmaceutical compounds). The results are shown in Fig. 1b and c. In the case of DCP, the reaction is started with a high rate so that $95 \%$ of DCP is destructed within $2 \mathrm{~h}$. Second addition of formic acid gives rise to proceeding the reaction with similar rate. By termination of formic acid decomposition of DCP is stopped. For CFA, similar trend is observed but the mineralization degree achieved is lower.

The catalysts were characterized in order to explain the differences observed in catalytic activity. Fig. 2 contains TPR profiles of the samples, that shows for the Pd5Al sample only a desorption peak of $\beta-\mathrm{PdH}$, which means an almost total reduction of $\mathrm{PdO}$ at ambient temperature. ${ }^{7}$ In the presence of $\mathrm{Fe}$, the disappearance of the $\beta$ - $\mathrm{PdH}$ desorption peak is accompanied by the growth of peaks at areas $\mathrm{A}$ and $\mathrm{B}$, which means that iron suppresses $\beta$-PdH formation. ${ }^{8}$ In contrast, the reduction of $\mathrm{Fe}$ shifts to lower temperatures. In the TPR thermograms of the Pd5FeCI and Pd5Fe samples, the peak of area A shows much more $\mathrm{H}_{2}$ consumption (8.4 and 7 times respectively) than the thermogram of the FePd5 sample (see Table S1 in ESI $\dagger$ ). High merging for the Pd and Fe species is expected in the Pd5FeCI sample, which was synthesized by co-impregnation. It can be concluded that the peak appearing in area A corresponds to the simultaneous reduction of palladium and iron oxides, resulting in the generation of

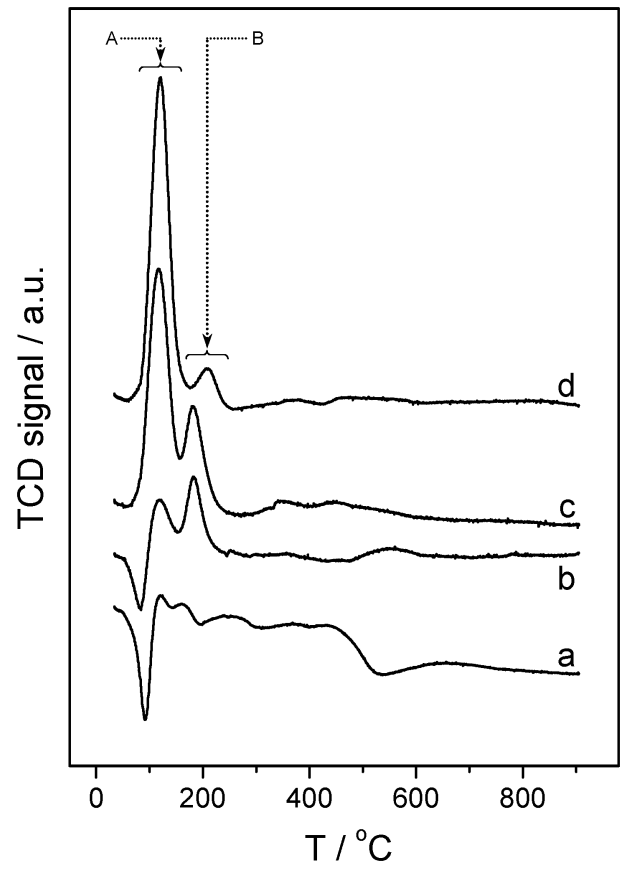

Fig. 2 TPR thermograms of the samples: (a) Pd5Al, (b) FePd5, (c) Pd5Fe and (d) Pd5FeCI. 
Pd-Fe alloy. ${ }^{9,10}$ The remarkable narrowness of the peak can be attributed to the uniform and well-dispersed iron and palladium oxide particles that yielded to very fine $\mathrm{Pd}-\mathrm{Fe}$ alloy particles. The second reduction in area $\mathrm{B}$ can be attributed to the partial iron oxide reduction still being affected by $\mathrm{Pd}$. The $\mathrm{Pd} 5 \mathrm{Fe}$ sample has a relatively high tendency towards $\mathrm{Pd}-\mathrm{Fe}$ alloy formation. In contrast, for the FePd5 sample, owing to the existence of $\beta-\mathrm{PdH}$, much of the Pd has not merged with the $\mathrm{Fe}$, and thus least tendency to alloy formation is observed.

In accordance with the TPR data, a HRTEM analysis of $\mathrm{Pd} 5 \mathrm{FeCI}$ and $\mathrm{Pd} 5 \mathrm{Fe}$ (Fig. 3A and B) revealed lattice fringes at $2.20 \AA$ for both samples. This value is within the (111) lattice fringes of the PdFe and $\mathrm{Pd}_{3} \mathrm{Fe}$ alloys at $2.19 \AA$ and $2.22 \AA$, respectively, and slightly below the value of the (111) crystallographic plane of metallic Pd (2.24 $⿱ 亠 ⿻ 口 卄)$. In addition to alloy particles, individual metallic $\mathrm{Pd}$ particles dispersed on alumina crystallites are also detectable in these two samples, but no isolated Fe-containing phases are observed. In contrast, the HRTEM analysis of the FePd5 sample (Fig. 3C) indicates the presence of metallic $\mathrm{Pd}$ and $\mathrm{Fe}_{2} \mathrm{O}_{3}$, which is identified by lattice fringes at $1.84 \AA$ and $2.21 \AA$ ascribed to (024) and (113) crystallographic planes, respectively.

In situ surface analysis by XPS during the reduction of the samples shows considerable reduction of $\mathrm{PdO}$ at $100{ }^{\circ} \mathrm{C}$ ( $>70 \%$ in all cases) (see Table 2), whereas the amount of reduced-surface iron is much higher for FePd5 (18.4\%) than for $\mathrm{Pd} 5 \mathrm{Fe}$ or $\mathrm{Pd} 5 \mathrm{FeCI}(0 \%$ and $6.5 \%$, respectively). Interestingly, reduction at $200{ }^{\circ} \mathrm{C}$ increases the amount of Fe reduced by up to $25.4 \%$ for FePd5 and, at the same time, slightly decreases the amount of $\mathrm{Pd}$ reduced (from $75 \%$ to $72.9 \%$ ), which suggests that the reduction of $\mathrm{Fe}_{2} \mathrm{O}_{3}$ occurs via electron transfer between metallic $\mathrm{Pd}$ and $\mathrm{Fe}_{2} \mathrm{O}_{3}$ particles. At this temperature, the amount of reduced-surface iron increases to a lower extent for $\mathrm{Pd} 5 \mathrm{Fe}$ and $\mathrm{Pd} 5 \mathrm{FeCI}$ samples (7.2 and $20.3 \%$, respectively). Thus, the order of sequential impregnation during the preparation of samples plays an important role in the final characteristics of the surface, which may account for the different activity in the Fenton reaction. The binding energy recorded for the $\mathrm{Fe}^{(+\delta)} \mathrm{p} 3 / 2$ core level is very close to that of $\mathrm{Fe}_{2} \mathrm{O}_{3} / \mathrm{Al}_{2} \mathrm{O}_{3}$ $(710.8 \mathrm{eV})$. This indicates that ionic iron species on the surface of the samples are mostly $\mathrm{Fe}^{3+} \cdot{ }^{11}$ Also, on the surface of $\mathrm{Pd}-\mathrm{Fe}$ alloy particles, $\mathrm{Fe}$ is mostly present as $\mathrm{Fe}^{3+}$, as was shown by Chen et al. ${ }^{12}$

Therefore, according to the above characterizations, firstly, close proximity and high interaction between the $\mathrm{Pd}$ and $\mathrm{Fe}$ species is observed. High stability of both metals indicated by leaching results can be due to such interaction. Secondly, for the Pd5FeCI and Pd5Fe samples, much of the Fe participates in alloy formation, whereas a weak tendency towards alloy formation is observed for FePd5. In contrast, the main species found for this sample are metallic $\mathrm{Pd}$ and $\mathrm{Fe}_{2} \mathrm{O}_{3}$.
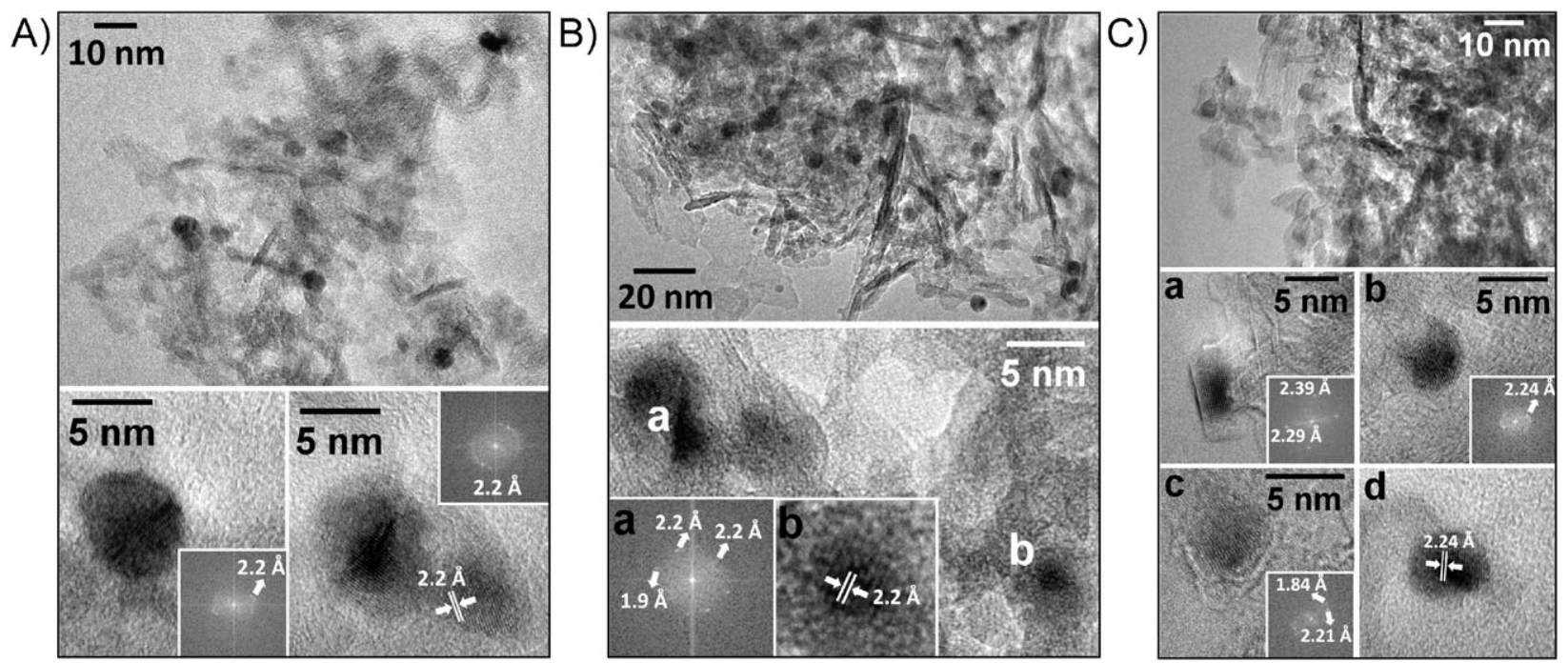

Fig. 3 HRTEM images of the following samples: (A) Pd5FeCI, (B) Pd5Fe and (C) FePd5.

Table 2 XPS quantitative results of the calcined and reduced Pd-Fe samples

\begin{tabular}{|c|c|c|c|c|c|c|c|c|}
\hline \multirow[b]{2}{*}{ Sample } & \multicolumn{4}{|c|}{ Binding energy/eV } & \multicolumn{4}{|c|}{ Elements contributions $(\%)$} \\
\hline & $\operatorname{Pd}(0) 3 \mathrm{~d} 5 / 2$ & $\operatorname{Pd}\left(\delta^{+}\right) 3 \mathrm{~d} 5 / 2$ & $\mathrm{Fe}(0) 2 \mathrm{p} 3 / 2$ & $\mathrm{Fe}\left(\delta^{+}\right) 2 \mathrm{p} 3 / 2$ & $\operatorname{Pd}(0)$ & $\mathrm{Pd}^{n+}$ & $\mathrm{Fe}(0)$ & $\mathrm{Fe}^{n+}$ \\
\hline Pd5FeCI calc. & - & 335.8 & - & 710.6 & 0 & 100 & 0 & 100 \\
\hline $\mathrm{Pd} 5 \mathrm{FeCI}$ red. $100{ }^{\circ} \mathrm{C}$ & 335.0 & 336.4 & 706.3 & 711.4 & 80.9 & 19.1 & 6.5 & 93.5 \\
\hline $\mathrm{Pd} 5 \mathrm{FeCI}$ red. $20{ }^{\circ} \mathrm{C}$ & 334.8 & 335.9 & 705.8 & 711.0 & 75.1 & 24.9 & 20.3 & 79.7 \\
\hline Pd5Fe calc. & - & 336.6 & - & $710.5 / 715.7$ & 0 & 100 & 0 & 100 \\
\hline Pd5Fe red. $100{ }^{\circ} \mathrm{C}$ & 335.4 & 336.9 & - & $711.2 / 717.0$ & 72.7 & 27.3 & 0 & 100 \\
\hline Pd5Fe red. $200{ }^{\circ} \mathrm{C}$ & 335.4 & 336.7 & 705.7 & 710.6 & 77.5 & 22.5 & 7.2 & 92.8 \\
\hline FePd5 calc. & - & 336.1 & - & 710.7 & 0 & 100 & 0 & 100 \\
\hline FePd5 red. $100^{\circ} \mathrm{C}$ & 335.4 & 336.8 & 706.8 & 711.5 & 75 & 25 & 18.4 & 81.6 \\
\hline $\mathrm{FePd} 5$ red. $200{ }^{\circ} \mathrm{C}$ & 335.2 & 336.4 & 706.3 & 710.8 & 72.9 & 27.1 & 25.4 & 74.6 \\
\hline
\end{tabular}




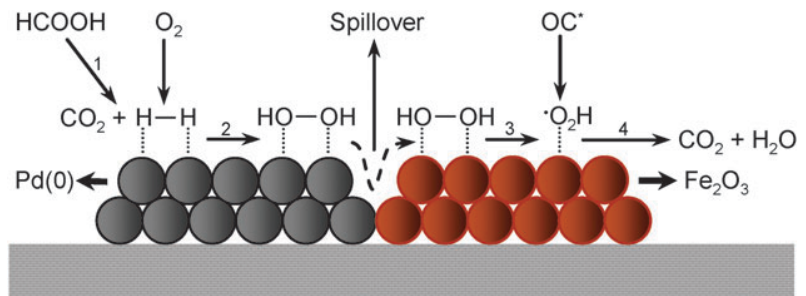

Scheme 1 Mechanism of the phenol degradation reaction via in situ generated $\mathrm{H}_{2} \mathrm{O}_{2}$ including: (1) decomposition of formic acid to $\mathrm{CO}_{2}$ and $\mathrm{H}_{2}$, (2) reaction of $\mathrm{O}_{2}$ with surface $\mathrm{H}_{2}$ to generate $\mathrm{H}_{2} \mathrm{O}_{2}$, (3) decomposition of chemisorbed $\mathrm{H}_{2} \mathrm{O}_{2}$ into radicals, (4) oxidation of organic compounds by surface radicals. OC*: organic compound.

The preference of the $\mathrm{Pd}-\mathrm{Fe}$ catalysts in mineralization with respect to the Pd5Al-ferrous ion coupling and CFP can be elucidated by a mechanistic model. In CFP, $\mathrm{H}_{2} \mathrm{O}_{2}$ is decomposed into hydroxyl radicals by dissolved ferrous ions. In a homogeneous system using the Pd5Al-ferrous ion, the hydrogen peroxide generated should be released into the solution to reach a soluble ferrous ion for radical formation. Over Pd-Fe catalysts, the mechanism can take the form of a spillover effect (Scheme 1) ${ }^{13}$ For surface species, the spillover effect mostly involves metallic $\mathrm{Pd}$ and $\mathrm{Fe}_{2} \mathrm{O}_{3}$. Based on that, formic acid decomposes to $\mathrm{CO}_{2}$ and $\mathrm{H}_{2}$ over metallic $\mathrm{Pd}$, which is followed by reaction with $\mathrm{O}_{2}$, leading to $\mathrm{H}_{2} \mathrm{O}_{2}$ formation. Then, surface chemisorbed $\mathrm{H}_{2} \mathrm{O}_{2}$ diffuses onto the $\mathrm{Fe}_{2} \mathrm{O}_{3}$ surface and, depending on the oxidation state of the $\mathrm{Fe}$, is decomposed into ${ }^{\bullet} \mathrm{OH}$ or ${ }^{\bullet} \mathrm{O}_{2} \mathrm{H}$ radical. ${ }^{14}$ In the last stage, the organic molecule approaches the radical and is oxidized to the oxidation products. Surface diffusion of activated $\mathrm{H}_{2} \mathrm{O}_{2}$ may also take place via alumina support. No spillover of chemisorbed $\mathrm{H}_{2} \mathrm{O}_{2}$ has been reported. It is important to say that the $\mathrm{Pd}-\mathrm{Fe}$ alloy may not favor the Fenton reaction; a close conjunction of metallic $\mathrm{Pd}$ and $\mathrm{Fe}_{2} \mathrm{O}_{3}$ particles would be more suitable. This conclusion is based on the better results obtained by the FePd5 catalyst.

In summary, a nearly total mineralization of phenol was achieved by a Fenton reaction over a Pd-Fe catalytic system. $\mathrm{H}_{2} \mathrm{O}_{2}$ was generated in situ by formic acid and $\mathrm{O}_{2}$ at ambient conditions. Degradation of chlorophenols and pharmaceutical compounds was also tested which indicated extensive capacity of the catalytic system in degradation of other categories of organic pollutants. The catalysts showed outstanding ability in a multi-step process that included $\mathrm{H}_{2} \mathrm{O}_{2}$ generation and the Fenton reaction. The catalysts are highly stable, as shown by the lack of $\mathrm{Pd}$ and $\mathrm{Fe}$ leaching, which represents a full heterogeneous Fenton process. These results suggest promising prospects for a one-pot full mineralization of organic pollutants.

This work was funded by MICINN projects CTM200802453 and CTQ2009-12520 and CIDEM project VALTEC 081-0052. We also thank MICINN for the funding given to S.C. through the Ramón y Cajal program. M.S.Y. acknowledges URV for the PhD grant. J.L. and F.M. acknowledge support from Catalan Government through the ICREA Academia awards.

\section{Notes and references}

1 J. J. Pignatello, E. Oliveros and A. Mackay, Crit. Rev. Environ. Sci. Technol., 2006, 36, 1; E. Brillas, I. Sirés and M. Oturan, Chem. Rev., 2009, 109, 6570.

2 (a) R. J. Bigda, Chem. Eng. Prog., 1995, 62; (b) R. Alnaizy and A. Akgerman, Adv. Environ. Res., 2000, 4, 233; (c) J. A. Zazo, J. A. Casas, A. F. Mahedano, M. A. Gilarranz and J. J. Rodriguez, Environ. Sci. Technol., 2005, 39, 9295.

3 M. S. Yalfani, S. Contreras, F. Medina and J. Sueiras, Appl. Catal. B: Environ., 2009, 89, 519.

4 S. Niwa, M. Eswaramoorthy, J. Nair, A. Raj, N. Ith, H. Shoji, T. Namba and F. Mizukami, Science, 2002, 295, 105; J. M. Campos-Martin, G. Blanco-Brieva and J. L. G. Fierro, Angew. Chem., Int. Ed., 2006, 45, 6962; J. J. Bravo-Suárez, K. K. Bando, T. Akita, T. Fujitani and T. J. Oyama, Chem. Commun., 2008, 3272.

5 M. S. Yalfani, S. Contreras, F. Medina and J. Sueiras, Chem. Commun., 2008, 3885.

6 E. M. Cordi and J. L. Falconer, J. Catal., 1996, 162, 104.

7 F. Pinna, F. Menegazzo, M. Signoretto, P. Canton, G. Fagherazzi and N. Pernicone, Appl. Catal. A: Gen., 2001, 219, 195.

8 F. J. Berry, L. E. Smart, P. S. Sai Prasad, N. Lingaiah and P. Kanta Rao, Appl. Catal. A: Gen., 2000, 204, 191.

9 F. Pinna, M. Selva, M. Signoretto, G. Strukul, F. Boccuzzi, A. Benedetti, P. Canton and G. Fagherazzi, J. Catal., 1994, 150, 356.

10 G. Leitz, M. Nimz, J. Völter, K. Lázár and L. Guczi, Appl. Catal., 1988, 45, 71

11 A. P. Grosvener, B. A. Kobe, M. C. Biesinger and N. S. McIntyre, Surf. Interface Anal., 2004, 36, 1564.

12 J. Chen, X. K. Sun, M. C. Yang, J. Xu, W. X. Chen, W. D. Wei and Z. Q. Hu, Appl. Surf. Sci., 1993, 72, 267.

13 W. C. Conner and J. L. Falconer, Chem. Rev., 1995, 95, 759.

14 S.-S. Lin and M. D. Gurol, Environ. Sci. Technol., 1998, 32, 1417. 